JOURNAL OF ORTHOPAEDIC

SURGERY AND RESEARCH
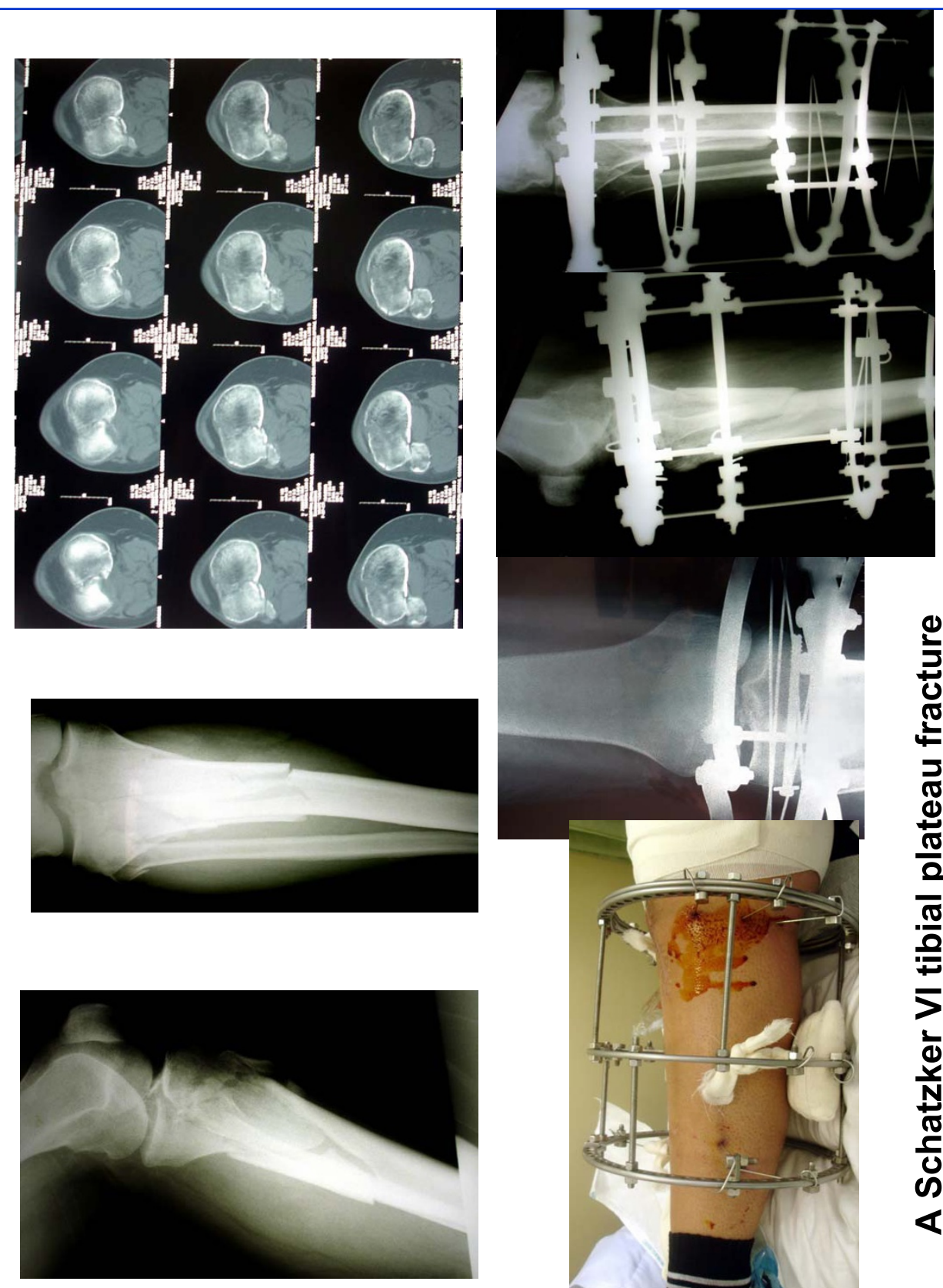

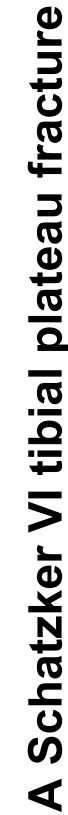

The use of twin-ring Ilizarov external fixator constructs: application and biomechanical proofof principle with possible clinical indications

Grivas and Magnissalis 


\title{
The use of twin-ring llizarov external fixator constructs: application and biomechanical proof- of principle with possible clinical indications
}

\author{
Theodoros B Grivas ${ }^{1 *}$ and Evangelos A Magnissalis ${ }^{2}$
}

\begin{abstract}
Background: In peri- or intra-articular fractures of the tibia or femur, the presence of short metaphyseal bone fragments may make the application of an llizarov external fixator (IEF) challenging. In such cases, it may be necessary to bridge the adjacent joint in order to ensure stable fixation. The twin-ring (TR) module of circular external fixation is proposed as an alternative method that avoids joint bridging, without compromising stability of fixation. The aim of this study is to present the experimental tests performed to compare the biomechanical characteristics of the single- and TR IEF modules. The clinical application of the TR module in select patients is also presented and the merits of this technique are discussed.

Methods: In this experimental study, the passive stiffness and stability of the single-ring (SR) and twin-ring (TR) IEF modules were tested under axial and shear loading conditions. In each module, two perpendicular wires on the upper surface and another two wires on the lower surface of the rings were used for fixation of the rings on plastic acetal cylinders simulating long bones.

Results: In axial loading, the main outcome measure was stiffness and the SR module proved stiffer than the TR. In shear loading, the main outcome measure was stability, the TR module proving more stable than the SR.

Discussion: The TR configuration, being stiffer in shear loading, may make joint bridging unnecessary when an IEF is applied. If it is still required, TR frames allow for an earlier discontinuation of bridging; either case is in favour of a successful final outcome.

Conclusion: The application of the TR module has led to satisfactory clinical outcomes and should be considered as an alternative in select trauma patients treated with an IEF. Biomechanically, the TR module possesses features which enhance fracture healing and at the same time obviate the need for bridging adjacent joints, thereby significantly reducing patient morbidity.
\end{abstract}

\section{Background}

In recent years, the use of the Ilizarov External Fixator (IEF) has been increasingly adopted for the management of complex intra- or peri-articular fractures of the knee and ankle joints. Also, the use of external fixation, based on Ilizarov principles, is invaluable in the management of difficult open tibial fractures [1].

Established indications for the application of IEF in acute trauma or the sequelae thereof include fractures

\footnotetext{
* Correspondence: tgri69@otenet.gr

'Orthopaedic and Trauma Department, "Tzanio" General Hospital of Piraeus,

Zanni and Afendouli 1, GR-185 36, Piraeus, Greece

Full list of author information is available at the end of the article
}

in the anatomical vicinity of the knee and ankle joints, particularly those presenting with short bone fragments (e.g. a proximal tibial or a distal malleolar bone fragment), recalcitrant septic non-unions of the femur or tibia, complex fractures and non-unions of the distal femur (AO Types A1-2-3 and C1-2-3, where the distal segment is not amenable to internal fixation techniques), and cases of non- or mal-union of the foot and ankle [2-4]. Finally, the use of the IEF is also considered a viable treatment option in the management of periprosthetic distal femoral fractures (i.e. in the vicinity of a knee arthroplasty) and for elective cases, such as a proximal tibial osteotomy.

\section{Biomed Central}


In many of the cases listed above, surgical techniques other than the IEF) are likely to compromise the soft tissue envelope (such as conventional open reduction and internal plate fixation) as well as the quality of fracture fixation (such as intramedullary nailing in a distal femur with minimal distal bone stoke as in AO Type A1), resulting in a biologically and mechanically suboptimal environment for fracture healing, [5,6].

However, the functional outcome is also highly dependent on the condition of soft tissues before treatment [1].

When applying the IEF in those cases, the surgeon often has to negotiate peri-articular bone fragments of inadequate length for placement of a sufficient number of wires with satisfactory bony purchase; if this technical difficulty cannot be overcome, the mechanical aspect of fracture fixation is compromised, risking failure of the fracture to unite.

On the other hand, one must bear in mind that there are no adverse effects of obesity, age, smoking, neuropathy, or Charcot neuroarthropathy on the complication rates and the post-operative recovery, when the IEF is used [7].

Over the past few years, our surgical team has often managed those challenging cases by incorporating a twin-ring module within the IEF frame. We observed that the final clinical outcome of this technique has been extremely rewarding in most patients. The purpose of this paper is to present the technical details associated with the application of the twin-ring (TR) IEF module in a series of select trauma patients. We also present the results of the biomechanical testing performed to investigate the properties of the proposed configuration, in comparison to a conventional, singlering (SR) construct.

\section{Clinical cases and outcome}

\subsection{Clinical cases}

Between 2002 and 2009, our surgical team has several times used a TR module within IEF constructs, in perior intra-articular fractures of the femur or tibia with fragments whose short length would not allow for adequate fixation. The application of the TR IEF module proved instrumental in overcoming this technical challenge.

Table 1 outlines the indications, patient details and outcome of the use of the TR IEF (clinical cases shown in Figures 1, 2, 3, 4, 5). As shown in Table 1, the TR IEF technique proved versatile enough to manage an array of metaphyseal fractures of long bones of the lower extremities (distal femoral, proximal and distal tibial fractures, metaphyseal/epiphyseal fractures).

\subsection{Clinical outcome}

The TR IEF concept demonstrated clinically relevant and ergonomically sound surgical features. The use of a TR IEF for metaphyseal/epiphyseal fractures around the knee joint or at the ankle joint provided surgeons with the option of an earlier-than-usual de-bridging of theses joints or even no bridging of the involved joint at all, thus leading to their faster mobilization of the knee or ankle joints. The overall outcome (clinical and functional) was satisfactory. There were no major postoperative complications apart the usual problem of pin site

Table 1 The overall indications for use of the twin-ring IEF construct and our clinical cases and their outcome

\begin{tabular}{|c|c|c|c|c|c|}
\hline $\begin{array}{l}\text { anatomical } \\
\text { site }\end{array}$ & type of \# & cases & $\begin{array}{c}\text { cases } \\
\text { treated with } \\
\text { IEF } \\
\text { involving a } \\
\text { TR module }\end{array}$ & $\begin{array}{l}\text { total } \\
\text { IEF } \\
\text { time }\end{array}$ & adjacent joint debridging \\
\hline \multirow[t]{3}{*}{ distal femur } & $\begin{array}{l}\text { supracondylar \# } \\
\text { AO: } \mathrm{A} 1,2,3 \mathrm{C} 1,2,3\end{array}$ & 51 & $8(15.7 \%)$ & $\begin{array}{l}\approx 16 \\
w k s\end{array}$ & knee: $\approx 5-6$ wks earlier \\
\hline & periprosthetic TKR \# & 1 & 1 & $\begin{array}{l}\approx 16 \\
w k s\end{array}$ & knee: $\approx 5-6$ wks earlier \\
\hline & $\begin{array}{c}\text { as above, with delayed healing or non- } \\
\text { union }\end{array}$ & 1 & 1 & $\begin{array}{c}\approx 18 \\
\text { wks }\end{array}$ & knee: $\approx 5-6$ wks earlier \\
\hline \multirow[t]{2}{*}{$\begin{array}{l}\text { proximal } \\
\text { tibia }\end{array}$} & condylar (plateau) \# Schatzker V and VI & 10 & 10 & $\begin{array}{l}\approx 12 \\
\text { wks }\end{array}$ & knee: 4-5 wks earlier \\
\hline & $\begin{array}{l}\text { upper tibial osteotomy for management } \\
\text { of early OA onset in young patients }\end{array}$ & 1 & 1 & $\begin{array}{l}\approx 13 \\
\text { wks }\end{array}$ & (benefit of no knee bridging) \\
\hline \multirow[t]{3}{*}{ distal tibia } & supramalleolar \# & 10 & 10 & $\begin{array}{l}\approx 16 \\
\text { wks }\end{array}$ & $\begin{array}{l}\text { (benefit of no ankle bridging) or if the ankle will be } \\
\text { bridged then Ankle jt debridging } \approx 3-4 \text { wks earlier }\end{array}$ \\
\hline & pilon \# & 5 & 5 & $\begin{array}{l}\approx 14 \\
\text { wks }\end{array}$ & ankle: $<5$ wks earlier \\
\hline & pilon \# with involv. of distal tibial 3rd & 1 & 1 & $\begin{array}{l}\approx 16 \\
\text { wks }\end{array}$ & ankle: $<4$ wks earlier \\
\hline
\end{tabular}



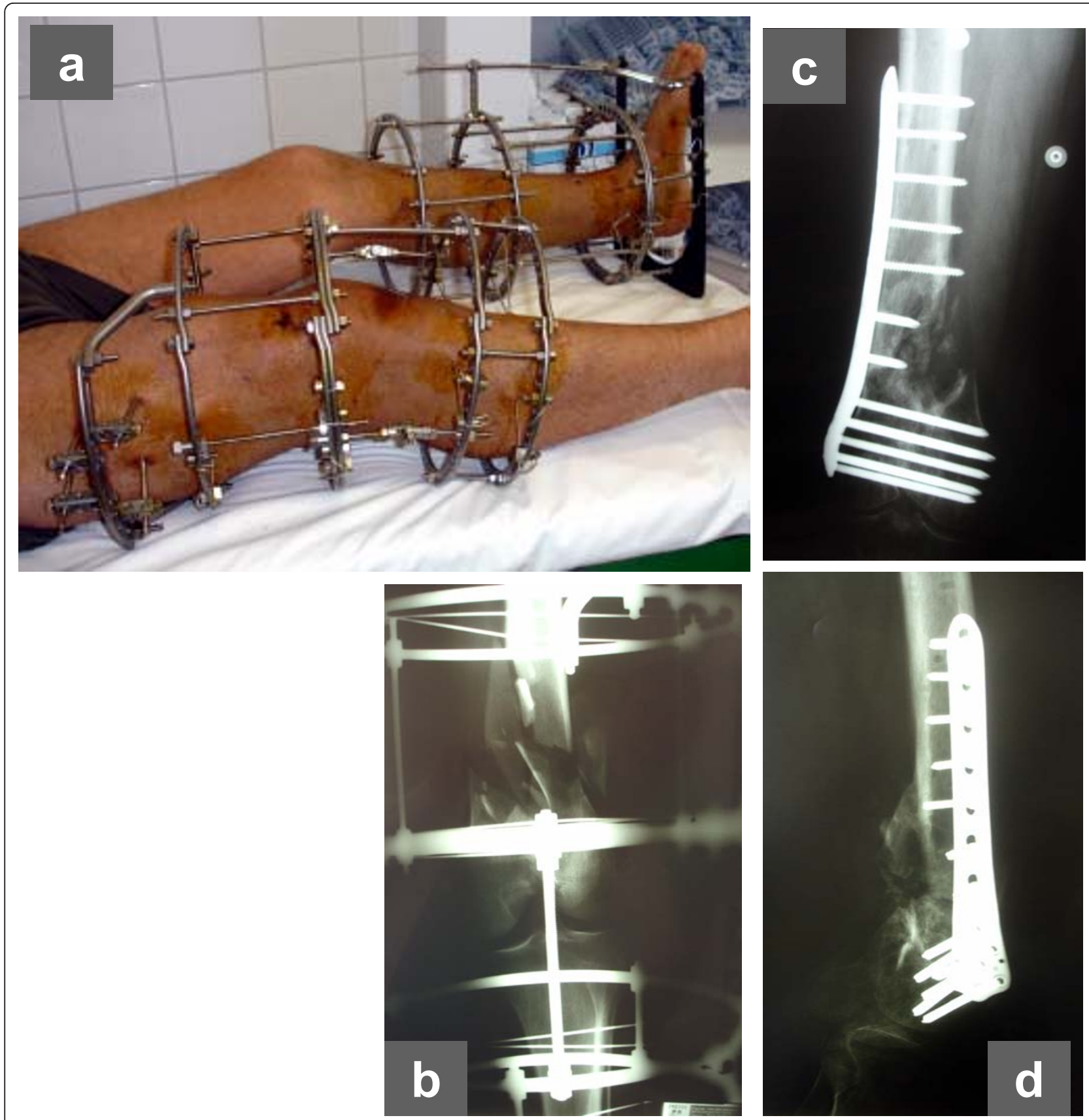

Figure 1 In a multi-trauma patient treated with circular external fixator, the TR configuration was applied for the fixation of a) a right open, supracondylar femoral fracture and b) a left distal tibial (pilon) fracture (a). Both were high-energy injuries, resulting in severe fracture comminution and segmental bone loss from the femur at the accident site (b). Bridging of the right knee and left ankle joints was deemed necessary. Subsequently, the femoral fracture was grafted and internally fixed $(c, d)$.

infections, that was managed with frequent wound dressing, antibiotics and infrequently with relocation of the pins.

\section{Biomechanical testing}

We hypothesized that the clinical effectiveness of the TR IEF concept might be attributed to the increased thickness of the double ring $(2 \times 5.0=10.0 \mathrm{~mm})$ and the resultant increased vertical distance between its upper and lower wire levels, allowing for safe placement of up to 5 wires. As a matter of fact, this advantage was first perceived on the basis of subjective surgical judgment, providing qualitative hints to a more rigid and, therefore, mechanically sound construct. In order to 

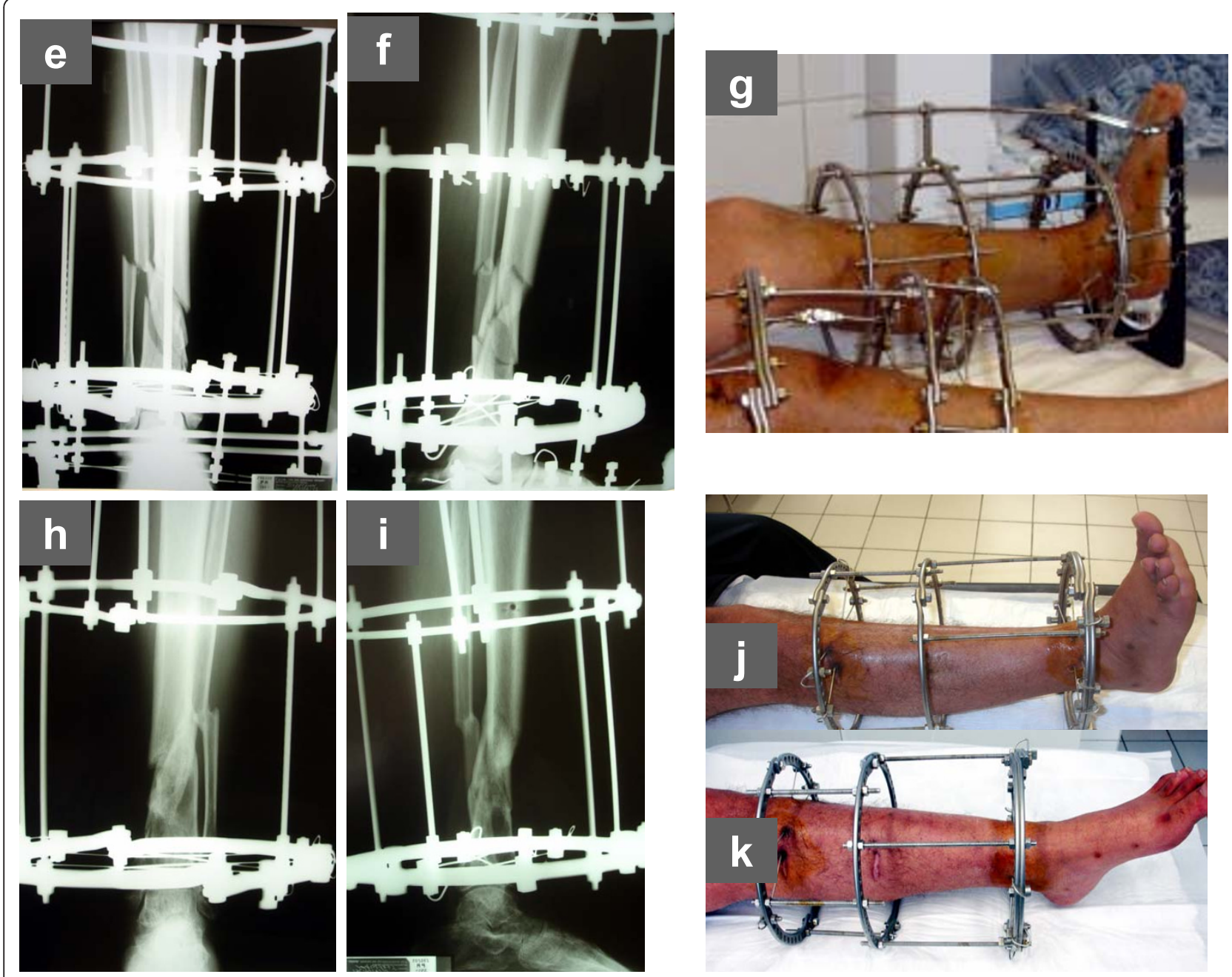

Figure 2 In the patient of Figure 1, the twin-ring configuration allowed for earlier discontinuation of bridging of the ankle joint $(e, f, g)$ during the healing period and faster joint mobilization at follow-up (h, i, j, k)

validate those assumptions objectively, a series of biomechanical tests was designed, as follows.

\subsection{Preparation of module specimens}

The aim of biomechanical testing was to characterize the behaviour of single-ring (SR) vs. twin-ring (TR) IEF modules and provide proof-of-principle laboratory documentation, in a comparative manner. In order to isolate the intrinsic characteristics of the two modules, we decided to run cyclic axial and shear tests on the simplest assembly configurations possible.

The SR and TR modules consisted of two and four half-rings, respectively, all of an internal diameter of 200 $\mathrm{mm}$ (Cat No 10-1308). Standard Ilizarov system accessory parts (screws, washers, nuts) and $1.8 \mathrm{~mm}$ wires (bayonet style; Cat No 10-2102) were used to assemble the full rings and connect them to purpose-built bonesimulating models. Those were plastic acetal cylindrical parts (diameter $30 \mathrm{~mm}$ ) meant to be loaded either axially (axial loading) or transversely (shear loading), simulating the proximal bone fragments. Precise drilling ensured appropriate insertion of Ilizarov wires at predefined transverse directions.

In both modules, four wires were used: two were drilled perpendicular to each other and were transfixed onto the upper ring surface. Another two wires were drilled at $45^{\circ}$ to the first two and were attached on the lower surface of the ring. All ring-bolt connections were tightened to 10 $\mathrm{Nm}$ with an adjustable dynamometric screwdriver (model A404, Facom, France). All wires were tensioned to a level of 130 using the system's dynamometric wire tensioner (Cat No 10-3101), prior to nut tightening.

\subsection{Testing apparatus and protocol}

A materials testing machine (Imperial 2500, MECMESIN, UK) with a $1 \mathrm{kN}$ load cell (ILC $1000 \mathrm{~N}$, 


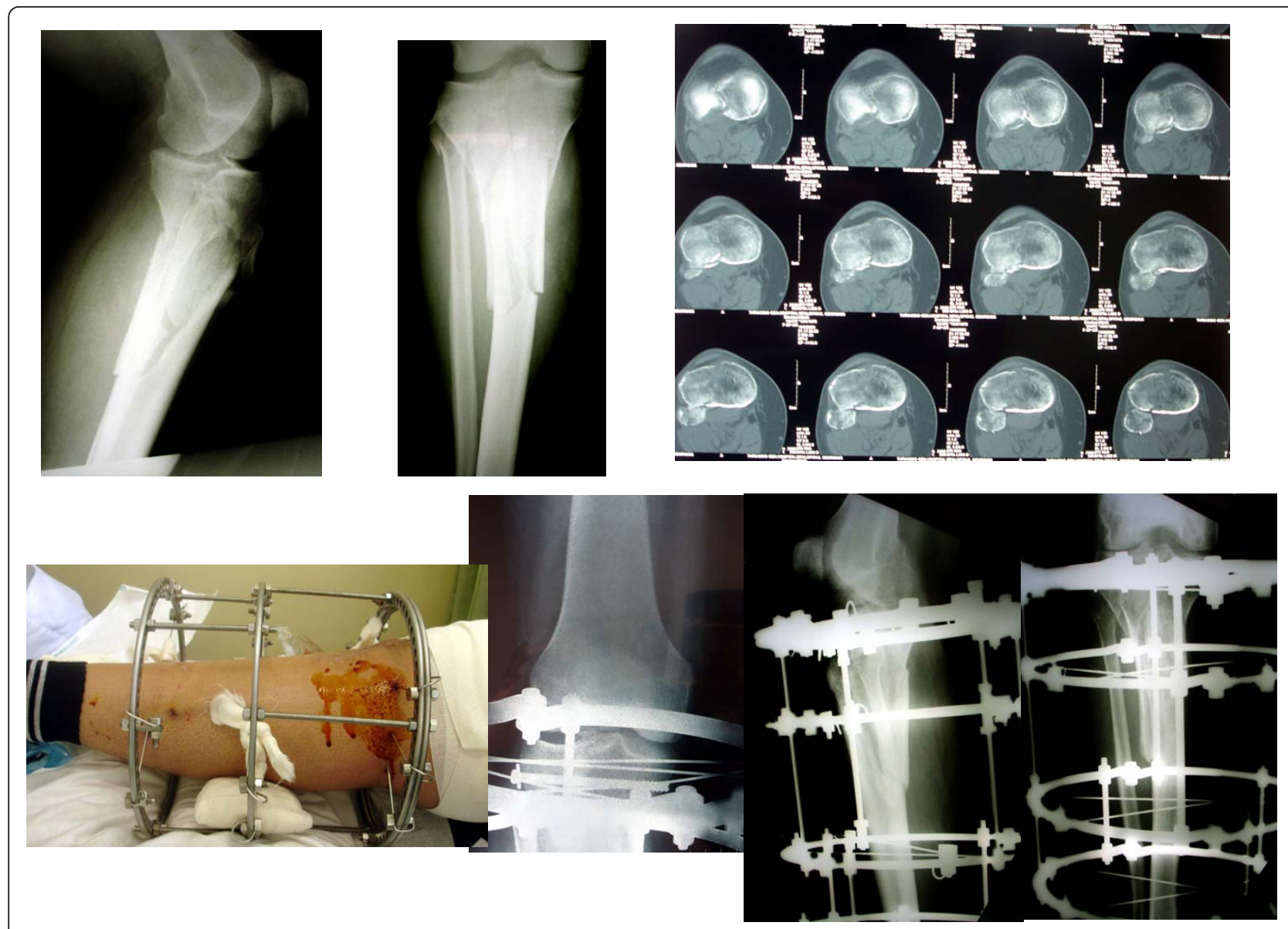

Figure 3 A Schatzker type VI tibial plateau fracture treated with an llizarov frame featuring a twin-ring proximally in order to stabilize adequately the fracture and allow the knee joint to be mobilized as soon as possible. The congruity of the joint line has been restored.

MECMESIN, UK) was equipped with a device especially designed to accommodate, mount and load the SR and TR modules. This device comprised robust horizontal and vertical steel plates, as well as cannulated posts and $5 \mathrm{~mm}$-thick washers used as spacers, when necessary, to negotiate step-height differences. A series of eight long M6 bolts were used to distally fix SR and TR specimens onto the device, in a safe circumferential configuration.

A vertical displacement, input from the load cell to the bone substitute, was applied to create the required loading configurations, as follows:

- axial loading (AX) was applied with the plane of SR and TR rings horizontal (Figure 6),

- shear loading (SH) was applied with the plane of SR and TR rings vertical (Figure 7).

The load cell was equipped with a loading rod connected to the bone model through a freely pivoting pin. In both loading configurations, various cyclic loading regimens were tested (Table 2). The testing machine was always in displacement control (i.e. controlling testing speed). With a sampling frequency of $100 \mathrm{~Hz}$, load, displacement and time were recorded.

\subsection{Statistical analysis}

The biomechanical differences between TR and SR were analyzed by means of a Mann-Whitney Rank Sum Test (using SigmaStat version 3.11, Systat Software, Inc.).

\section{Results}

For all axial and shear loading tests, comparative graphs of load vs. displacement were obtained (Figures 8, 9). The effective passive stiffness of each ring module was assessed by calculating the slope values $(\mathrm{N} / \mathrm{mm})$, based on linear trends between zero and maximum displacement points (Tables 3, 4).

The mean biomechanical responses of TR and SR modules may be summarized as follows: in axial loading, the TR module demonstrated a lower stiffness than the SR module $(71.4 \pm 3.0 \mathrm{~N} / \mathrm{mm}$ vs. $94.4 \pm 2.9 \mathrm{~N} / \mathrm{mm}$, respectively), while in shear loading the stiffness of the 


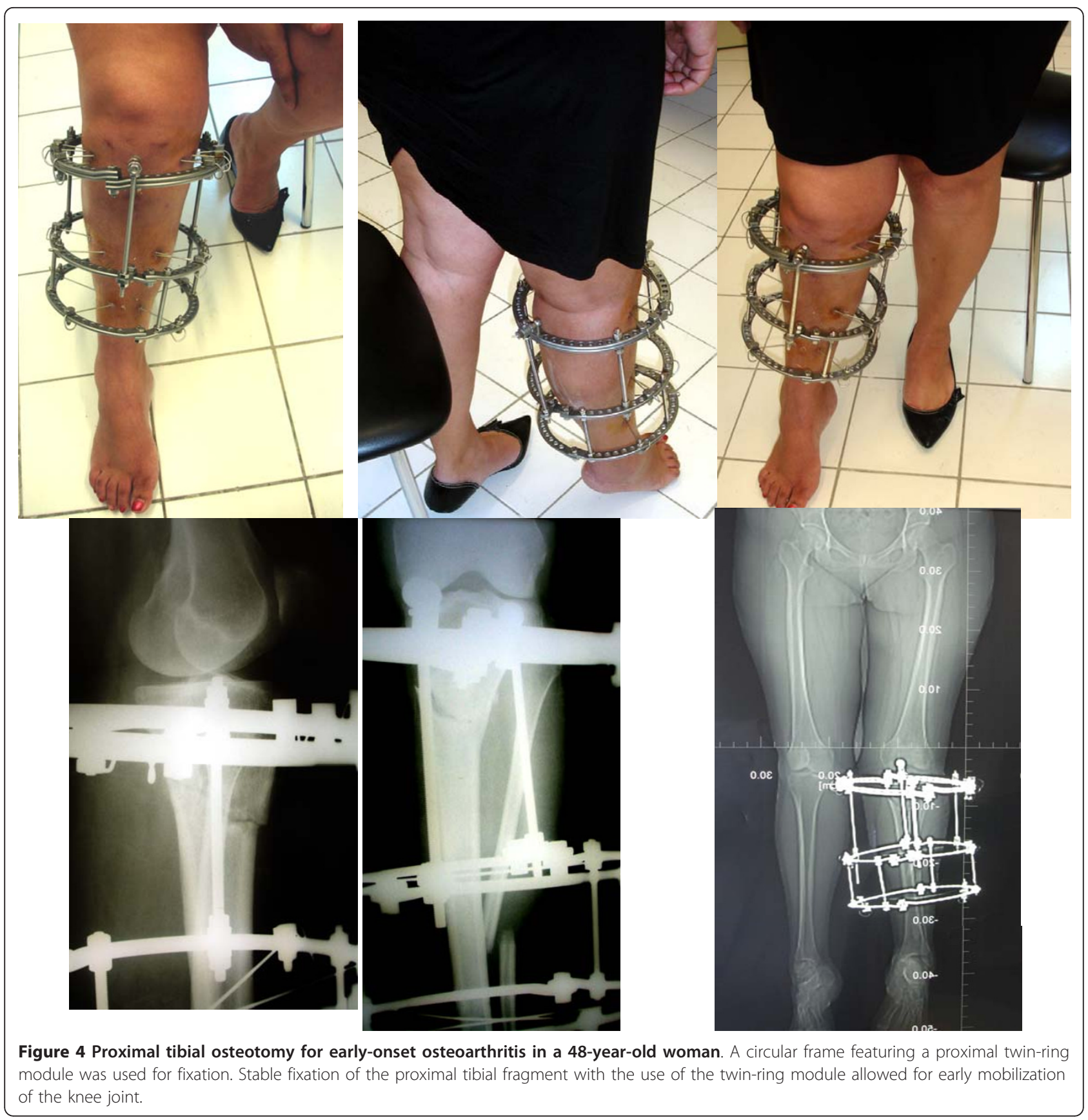

TR was higher than that of the SR module $(27.9 \pm 1.3$ $\mathrm{N} / \mathrm{mm}$ vs. $18.5 \pm 5.3 \mathrm{~N} / \mathrm{mm}$, respectively).

These biomechanical differences between TR and SR were found to be statistically significant $(p<0.001)$, both in axial and shear loading, (Mann-Whitney Rank Sum Test).

\section{Discussion}

When treating trauma patients with an IEF, the surgeon is not infrequently faced with the challenge of fractures involving relatively short-length bone fragments (for instance, in the proximal or distal tibial metaphysis). In those circumstances, it may be necessary to extend the frame beyond the involved joint in order to maximize the mechanical stability of the construct. In doing so, however, this joint is unnecessarily "locked" in place together with the fractured bone fragments. The resultant immobilisation of the articular surfaces may have detrimental implications for the final outcome as it is classically known that immobilization of the articular surfaces is associated with adverse sequelae, including stiffness or even arthritis. 

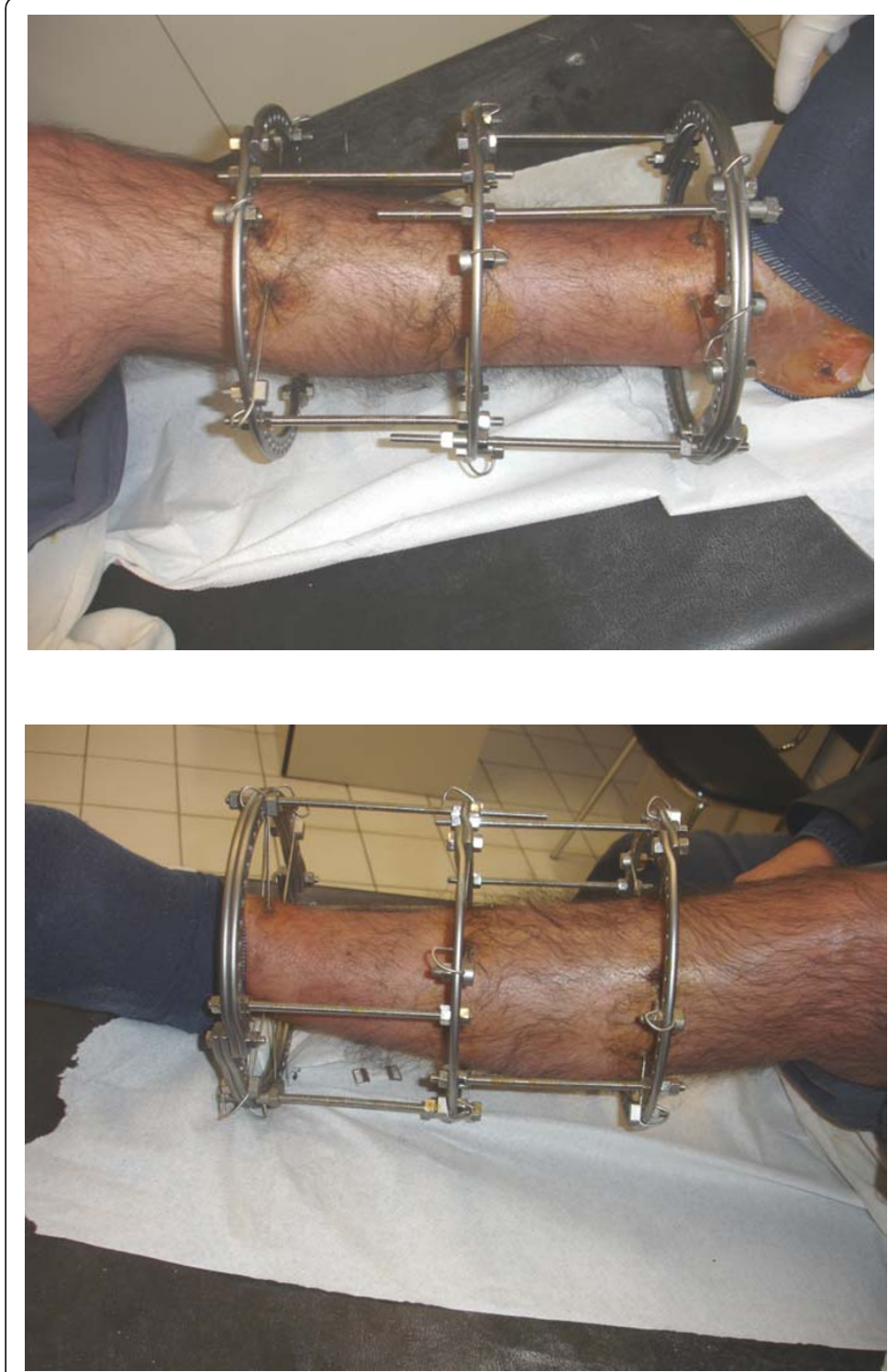
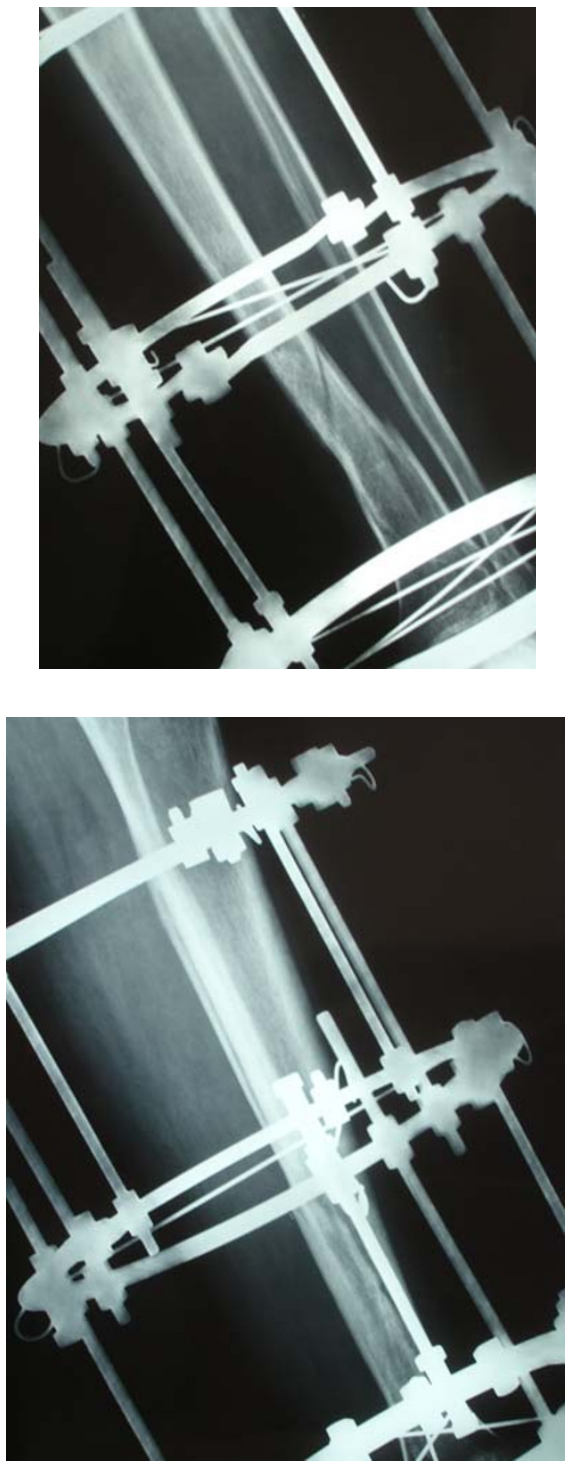

Figure 5 A twin-ring module used in a circular frame for fixation of a distal tibial fracture. The fracture line in these injuries frequently extends to the ankle joint, and the injury becomes a pilon fracture.

As an alternative, it was thought that a twin-ring module could be used for the ring located adjacent to the short bone fragment. Our surgical team has proudly observed satisfactory clinical and functional outcomes in select trauma cases where the twin-ring module was used. It remained to be proven, however, that this configuration possessed adequate mechanical features. As a proof-of-principle procedure, we decided to run a series of biomechanical tests, in order to comparatively characterize the behaviour of single- and twin-ring IEF modules.

In axial loading, curves of load vs. displacement demonstrated a trend which was close to linear at low amplitudes $( \pm 3 \mathrm{~mm})$ and less so at higher $( \pm 5$ and \pm 7 $\mathrm{mm}$ ) amplitudes. In all cases, however, trends were continuous and quite regular, enabling us to quantify values of passive stiffness as the linear slopes between the zero and maximum displacement points. In all instances, the TR module demonstrated clearly lower values of passive stiffness than the SR module. The phenomenon of wirepretension-loss during axial loading (long recognized and still investigated for IEF [8-12], although not detrimental in any case, is expected to be more clearly manifested in TR rather SR modules; since the increased vertical distance of TR wire levels induces successive rather than simultaneous loading of wire levels and 


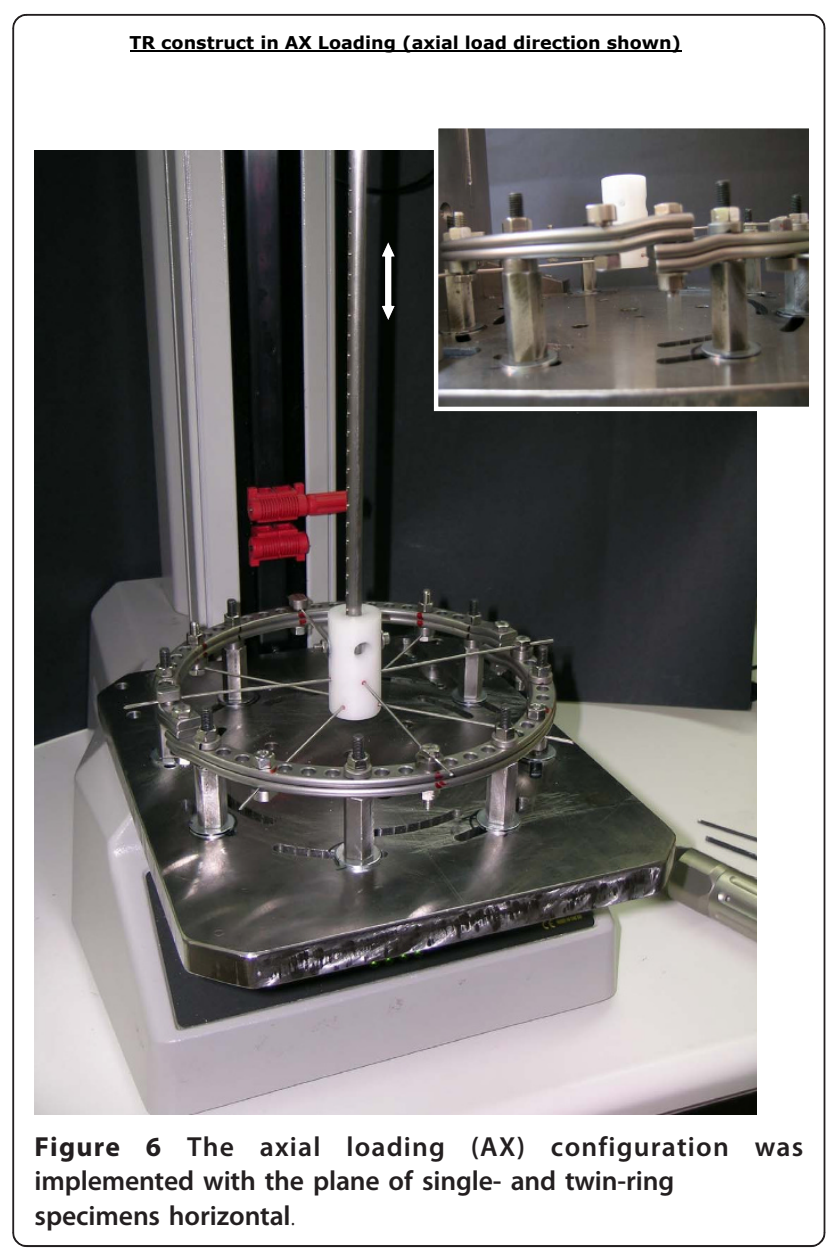

therefore a less stiff behaviour. In the current context of TR modules, a lower stiffness in axial loading is thought to be beneficial, as it allows for the necessary axial micromotion and consequent compression between bone fragments [13].

In shear loading, curves of load vs. displacement demonstrated a trend consisting of distinct loops. The loops had a longer dimension along the $\mathrm{x}$ - (displacement) than along the y-axis (load). This pattern can be explained by the fact that, upon application of shear load, the plastic model simulating bone first slides against the wire aligned to the direction of load and then transfers the load to the construct. Our analysis deliberately ignored intermediate sliding events and was

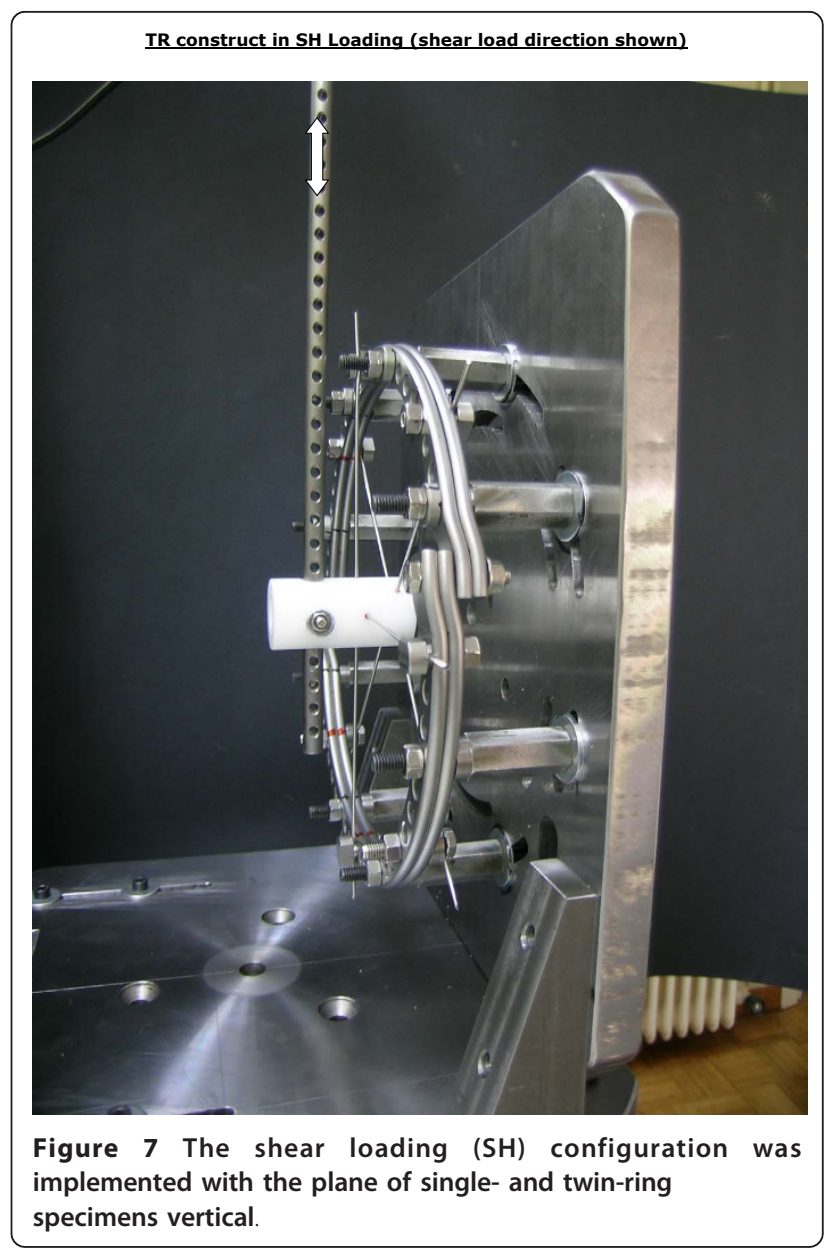

focused on the overall effective behavior of constructs instead. Therefore, it was conducted between zero and maximum displacement points. In all instances, the TR module demonstrated clearly higher values of passive stiffness than the SR module. A higher stiffness in shear loading is thought to be beneficial because it resists motion along the axial (transverse) plane of bone segments, potentially jeopardizing, or even disorganizing, callus formation [14].

The present biomechanical study was conceived, designed and executed in order to comparatively provide an insight to the mechanical performance of single- and double-ring modules of Ilizarov constructs. By eliminating potential confounding factors, the experimental

Table 2 The tested cyclic loading regimes for Axial Loading and Shear Loading

\begin{tabular}{cccc}
\hline \multicolumn{2}{c}{ Axial Loading } & \multicolumn{2}{c}{ Shear Loading } \\
\hline displacement range $(\mathbf{m m})$ & testing speed (mm/minute) & displacement range $(\mathbf{m m})$ & testing speed $(\mathbf{m m} / \mathbf{m i n u t e})$ \\
\hline \pm 3.0 & 20 & \pm 3.0 & 30 \\
\hline \pm 5.0 & 30 & \pm 5.0 & 30 \\
\hline \pm 7.0 & 50 & & \\
\hline
\end{tabular}




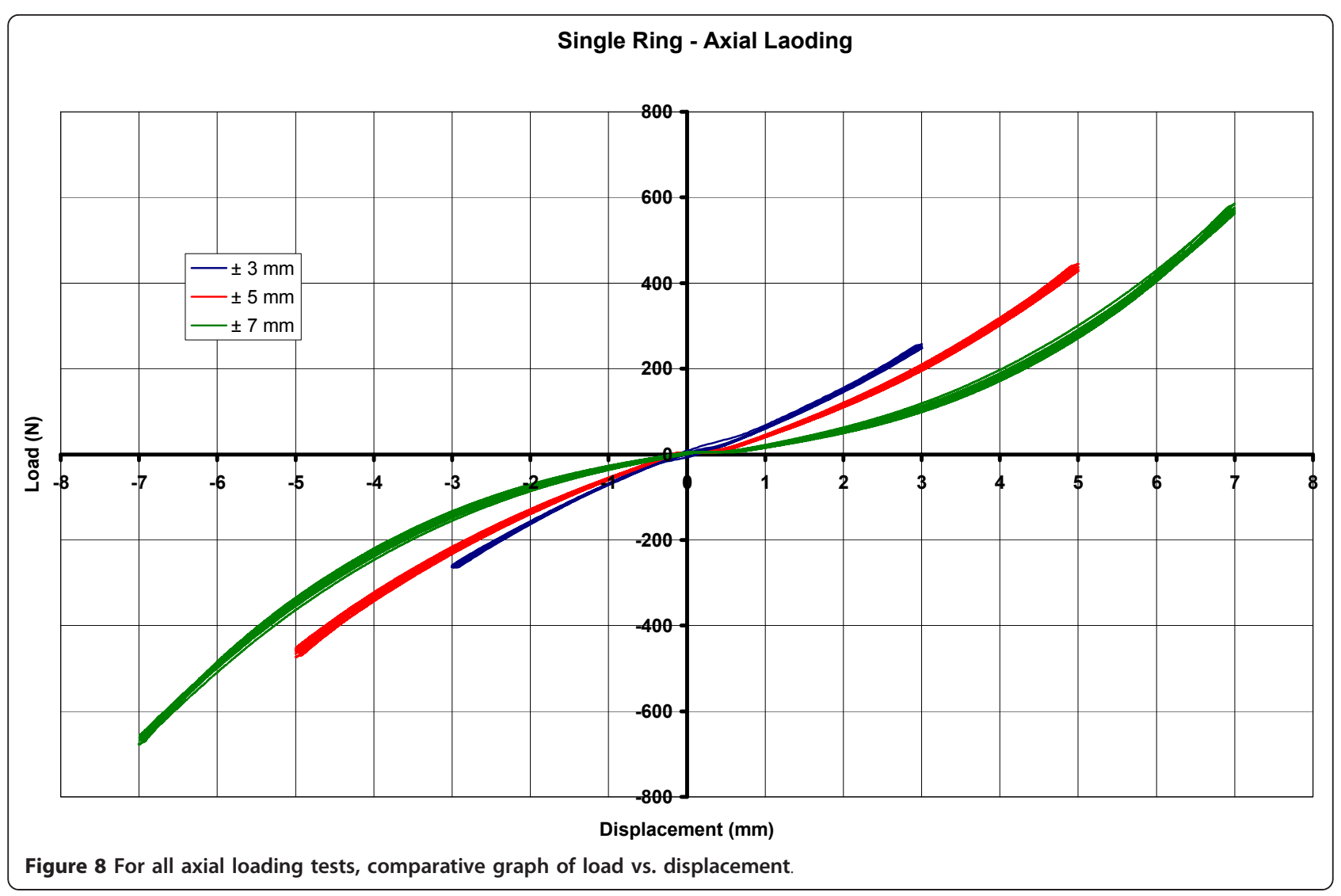

setup and methodology ensured a comparative demonstration of biomechanical events, leading to a set of reliable findings with clinical implications.

This work may be expanded (and further research is currently under way) to encompass more elaborate mechanical testing, with different wire configurations and loading conditions (e.g. torsion). Furthermore, in an effort to create a permanent numerical model of Ilizarov constructs, computational studies involving finite element modeling and analysis (FEM-FEA) on both module configurations, can be undertaken.

The results of the present study have implications in the clinical setting. In cases of knee and ankle intra- or peri-articular fractures, it is often considered necessary to extend the IEF so as to span the involved joint, for the purposes of increased stability in bending loads. By being stiffer in shear loading, use of the twin-ring configuration may achieve an equally stable fixation without the need to bridge a joint. If a surgeon still decides to span a joint, the twin-ring module allows for earlier removal of the frame. In either case, an optimal clinical outcome is more likely. Furthermore, and possibly more importantly, in the immediate postoperative period, when the limb is immobilized for a 2-3 week period, neovessel formation occurs at the fracture region [15]. After the initiation of weight-bearing, the twin-ring system is more flexible in axial loading. This increased flexibility exploits those neovessels and promotes fracture healing, while the increased shear stiffness prevents horizontal micromotion and development of a non- or mal-union.

It is accepted that pin loosening and subsequent pin track infection [16] is a problem of rather mechanical aetiology, and usually occurs at the proximal- or distalmost ends of the external fixator.

Pin track infection also appeared in some of our cases and was treated with meticulous local cleaning and dressing, antibiotics and rarely with pin exchange. In this report this IEF treatment complication is not mentioned in detail as we principally focus on the technical aspects of TR configuration.

This complication has been attributed to local bending effects, particularly those in the vicinity of joints and can be effectively addressed either by extending the construct across the joint or by locally increasing the number of wires. Both options aim at increasing mechanical stability and enhancing bony union. The latter, however, is preferable and can be implemented more easily in a TR IEF configuration. 


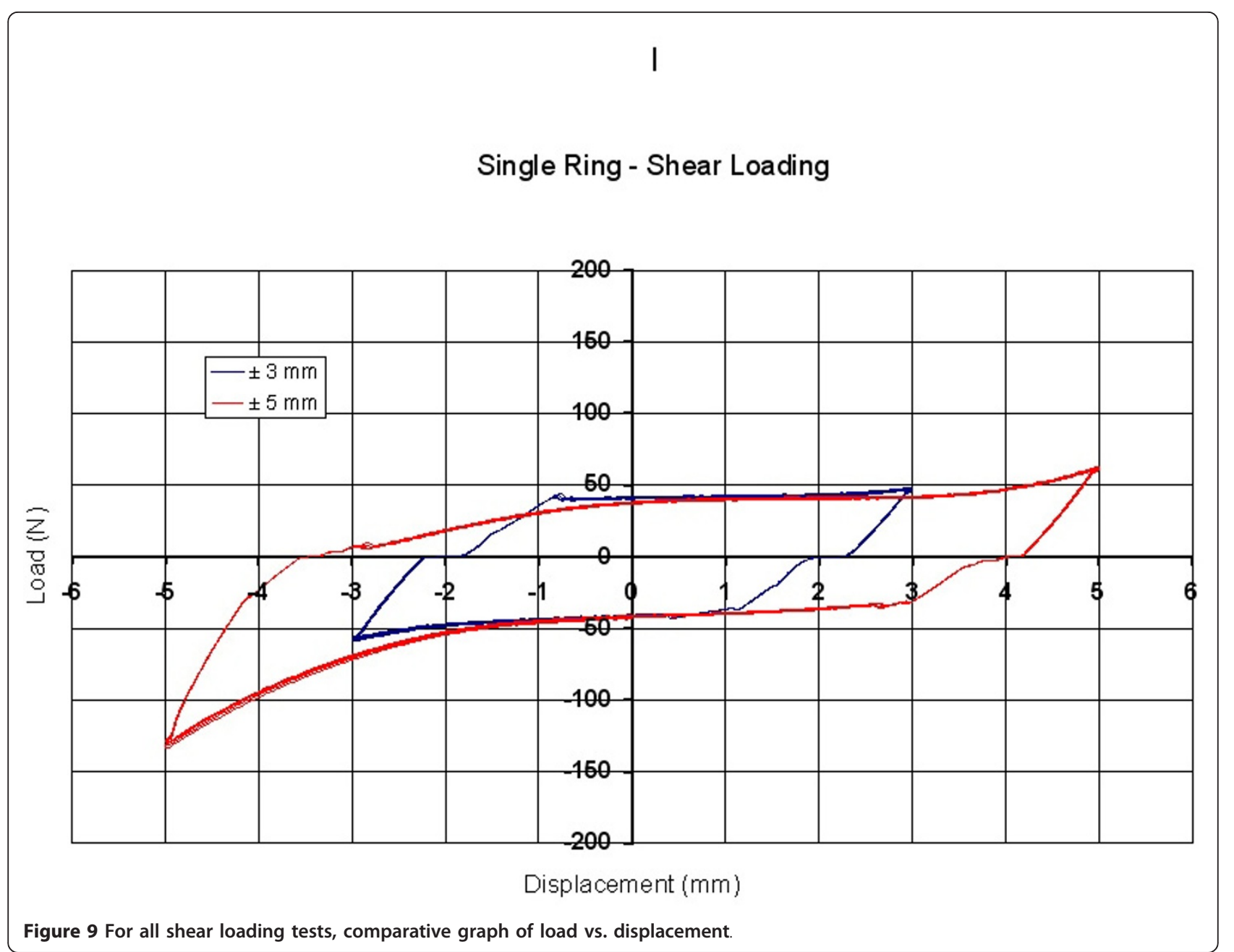

Table 3 AXIAL loading: Slope values in N/mm, characterizing the effective passive stiffness of ring modules, were calculated based on linear trends between zero and maximum displacement points

\begin{tabular}{|c|c|c|c|c|c|}
\hline \multicolumn{2}{|c|}{ Passive Stiffness Values Average \pm St.Deviation $(\mathrm{N} / \mathrm{mm})$} & \multicolumn{4}{|c|}{ AXIAL loading } \\
\hline & & negative direction & positive direction & both directions & overall \\
\hline \multirow[t]{3}{*}{ TWIN RING module } & $\pm 3 \mathrm{~mm}$ & $67.2 \pm 0.2$ & $69.1 \pm 0.2$ & $68.2 \pm 1.1$ & $71.4 \pm 3.0$ \\
\hline & $\pm 5 \mathrm{~mm}$ & $70.2 \pm 0.2$ & $75.1 \pm 0.1$ & $72.7 \pm 2.6$ & \\
\hline & $\pm 7 \mathrm{~mm}$ & $75.3 \pm 0.2$ & $71.2 \pm 0.2$ & $73.2 \pm 2.1$ & \\
\hline \multirow[t]{3}{*}{ SINGLE RING module } & $\pm 3 \mathrm{~mm}$ & $92.3 \pm 0.2$ & $92.2 \pm 0.4$ & $92.2 \pm 0.3$ & $94.4 \pm 2.9$ \\
\hline & $\pm 5 \mathrm{~mm}$ & $98.0 \pm 0.2$ & $95.1 \pm 0.2$ & $96.6 \pm 1.5$ & \\
\hline & $\pm 7 \mathrm{~mm}$ & $98.0 \pm 0.2$ & $91.1 \pm 0.3$ & $94.5 \pm 3.6$ & \\
\hline
\end{tabular}

Table 4 SHEAR loading: Slope values in N/mm, characterizing the effective passive stiffness of ring modules, were calculated based on linear trends between zero and maximum displacement points

\begin{tabular}{|c|c|c|c|c|c|}
\hline \multicolumn{2}{|c|}{ Passive Stiffness Values Average \pm St.Deviation $(\mathrm{N} / \mathrm{mm})$} & \multicolumn{4}{|c|}{ SHEAR loading } \\
\hline & & negative direction & positive direction & both directions & overall \\
\hline \multirow[t]{2}{*}{ TWIN RING module } & $\pm 3 \mathrm{~mm}$ & $26.8 \pm 0.1$ & $28.9 \pm 0.4$ & $27.9 \pm 1.1$ & $27.9 \pm 1.3$ \\
\hline & $\pm 5 \mathrm{~mm}$ & $29.3 \pm 0.5$ & $26.6 \pm 0.5$ & $28.0 \pm 1.5$ & \\
\hline \multirow[t]{2}{*}{ SINGLE RING module } & $\pm 3 \mathrm{~mm}$ & $19.3 \pm 0.6$ & $15.9 \pm 0.5$ & $17.6 \pm 1.9$ & $18.5 \pm 5.3$ \\
\hline & $\pm 5 \mathrm{~mm}$ & $26.4 \pm 0.6$ & $12.4 \pm 0.3$ & $19.4 \pm 7.4$ & \\
\hline
\end{tabular}


The TR Ilizarov construct possesses favourable biomechanical properties, which enhance fracture union and at the same time reduce complications arising from joint immobilization and pin/wire track infections. Our clinical outcomes, corroborated by the biomechanical proof-of-principle, are encouraging enough for us to recommend its continued use in patients with the appropriate clinical indications.

\section{Conclusions}

When treating select trauma patients, the application of the TR module in Ilizarov circular external fixators is suggested as a promising surgical alternative, offering satisfactory outcomes and reduced patient morbidity.

\section{Acknowledgements}

The authors wish to acknowledge Dr. Elias Vasiliadis for his help during the biomechanical testing and Dr. Nikolaos Bardakos for assisting in manuscript drafting.

\section{Author details}

'Orthopaedic and Trauma Department, "Tzanio" General Hospital of Piraeus, Zanni and Afendouli 1, GR-185 36, Piraeus, Greece. 'Laboratory for the Research of the Musculoskeletal System (LRMS), University of Athens, KAT Hospital Kifissia, Athens, Greece.

\section{Authors' contributions}

TBG introduced the twin llizarov ring configuration, was the surgeon of all the treated patients with this TR module, described the indications of treatment, was responsible for conception and supervision of the study, planning of the experiments, and drafting the manuscript. EAM was responsible for planning of the experiments, performed the biomechanical testing and contributed with analysis of the data and drafting of the manuscript. All authors read and approved the final manuscript.

\section{Competing interests}

The authors declare that they have no competing interests.

Received: 27 November 2010 Accepted: 11 August 2011

Published: 11 August 2011

\section{References}

1. El-Rosasy MA: Appraisal of the role of external skeletal fixation in the management of sequelae of open tibial fractures. Indian J Orthop 2008, 42(4):420-425.

2. Madhusudhan Thayur R, Ramesh Balasundaram, Manjunath KS, Shah Harshad M, Sundaresh Dabir C, Krishnappa N: Outcomes of Ilizarov ring fixation in recalcitrant infected tibial non-unions-a prospective study. Journal of Trauma Management \& Outcomes 2008, 2:6.

3. Cavusoglu AT, Ozsoy MH, Dincel VE, Sakaogullari A, Basarir K, Ugurlu M: The use of a low-profile llizarov external fixator in the treatment of complex fractures and non-unions of the distal femur. Acta Orthop Belg 2009, 75(2):209-18

4. Molloy AP, Roche A, Narayan B: Treatment of nonunion and malunion of trauma of the foot and ankle using external fixation. Foot Ankle Clin 2009, 14(3):563-87

5. Krettek C, Müller M, Miclau T: Evolution of minimally invasive plate osteosynthesis (MIPO) in the femur. Injury 2001, 32(Suppl 3):SC14-23.

6. Neubauer T, Wagner M: Current status of minimally invasive plate osteosynthesis: specific part II. Unfallchirurg 2009, 112(11):981-995.

7. Wukich DK, Belczyk RJ, Burns PR, Frykberg RG: Complications encountered with circular ring fixation in persons with diabetes mellitus. Foot Ankle Int 2008, 29(10):994-1000.
8. Aronson J, Harp JH Jr: Mechanical considerations in using tensioned wires in a transosseous external fixation system. Clin Orthop Relat Res 1992, 280:23-29.

9. Delprete C, Gola MM: Mechanical performance of external fixators with wires for the treatment of bone fractures-Part II: Wire tension and slippage. J Biomech Eng 1993, 115(1):37-42.

10. Mullins MM, Davidson AW, Goodier D, Barry M: The biomechanics of wire fixation in the llizarov system. Injury 2003, 34(2):155-157.

11. Watson MA, Mathias KJ, Maffulli N, Hukins DW: The effect of clamping a tensioned wire: implications for the Ilizarov external fixation system. Proc Inst Mech Eng H 2003, 217(2):91-98.

12. Aquarius R, Van Kampen A, Verdonschot N: Rapid pre-tension loss in the Ilizarov external fixator: an in vitro study. Acta Orthop 2007, 78(5):654-660.

13. Jagodzinski $M$, Krettek $C$ : Effect of mechanical stability on fracture healing-an update. Injury 2007, 38(Suppl 1):S3-10.

14. Park SH, O'Connor K, McKellop H, Sarmiento AJ, Luck Vernon Sr: The influence of active shear or compressive motion on fracture-healing. $J$ Bone Joint Surg Am 1998, 80(6):868-78.

15. Mohanti RC, Mahakul NC: Vascular response in fractured limbs with and without immobilisation: an experimental study on rabbits. Int Orthop 1983, 7(3):173-7.

16. Blum AL, BongioVanni JC, Morgan SJ, Flierl MA, dos Reis FB: Complications associated with distraction osteogenesis for infected nonunion of the femoral shaft in the presence of a bone defect: a retrospective series. J Bone Joint Surg Br 2010, 92(4):565-70.

doi:10.1186/1749-799X-6-41

Cite this article as: Grivas and Magnissalis: The use of twin-ring llizarov external fixator constructs: application and biomechanical proof-of principle with possible clinical indications. Journal of Orthopaedic Surgery and Research 2011 6:41.

\section{Submit your next manuscript to BioMed Central and take full advantage of:}

- Convenient online submission

- Thorough peer review

- No space constraints or color figure charges

- Immediate publication on acceptance

- Inclusion in PubMed, CAS, Scopus and Google Scholar

- Research which is freely available for redistribution

Submit your manuscript at www.biomedcentral.com/submit
C Biomed Central 